\title{
Physical and mechanical properties of ghora neem (Melia azedarach) plywood
}

\author{
M. K. Rahman ${ }^{1}$, M. Asaduzzaman ${ }^{1}$, M. M. Rahman ${ }^{1}$, A. K. Das ${ }^{2 *}$, S. K. Biswas ${ }^{2}$ \\ ${ }^{1}$ Forestry and Wood Technology Discipline, Khulna University, Khulna-9208, Bangladesh \\ ${ }^{2}$ Pulp and Paper Technology, Asian Institute of Technology, Thailand
}

\begin{abstract}
This paper gives the results of ghora neem (Melia azedarach) plywood for assessing it as an alternative raw material for plywood industries. Five ply ghora neem plywood of $2400 \mathrm{~mm} \times 1200 \mathrm{~mm} \times 12 \mathrm{~mm}$ size was manufactured using urea formaldehyde adhesive. The important physical and mechanical properties were examined for assessing its quality. The results of physical and mechanical properties of ghora neem plywood were compared with the data obtained with existing market available plywood manufactured with shimul (Bombax ceiba). The density of ghora neem plywood and shimul plywood was 541.00 and $499.80 \mathrm{~kg} / \mathrm{m}^{3}$ respectively. The MOR was $58.33 \mathrm{~N} / \mathrm{mm}^{2}$ for ghora neem plywood while it was $32.52 \mathrm{~N} / \mathrm{mm}^{2}$ for the shimul plywood. The MOE was found for ghora neem plywood $3950.01 \mathrm{~N} / \mathrm{mm}^{2}$ and on the other hand, the shimul plywood showed $3224.15 \mathrm{~N} / \mathrm{mm}^{2}$. The ghora neem plywood showed better performance for both physical and mechanical properties and it also follows the standard.
\end{abstract}

Keywords: Melia azedarach; Physical properties; Mechanical properties; MOR (Modulus of Rupture); MOE (Modulus of Elasticity)

\section{Introduction}

Composite wood ranges from fiberboard to laminated beams and components. Convention wood composite materials fall into five main categories based on the physical configuration of the wood used to make the products: plywood, oriented strand board, particleboard, hardboard and cellulosic fiberboard (Youngquist, 1988). The plywood manufacturing process in unique, as a raw material is manufactured into a product that is stronger than or as strong as the original tree (Baldwin, 1981). Plywood is often named as the first from the group of products which are known as engineered wood at present (Hrázský and Král, 2007). Plied veneered materials overcome largely three crucial drawbacks of solid wood by their construction arrangement: material anisotropy and heterogeneity, insufficient dimensional stability in the course of changes in the moisture content and problems in creating large areas and forms (Král and Hrázský, 2006).

Although timber is the principle raw material for manufacture of plywood, all timber species are not equally suitable for large scale manufacture of any type of plywood. Physical characters of timber, its availability in bulk quality and price factor are dependent for choosing timber as a raw material for plywood (Zaman, 1982). The homestead and village groves of Bangladesh have about 150 tree species (Das, 1990). Among 150 tree species of Bangladesh only a few of them are being used by the plywood, tea chest and particle board industries. Sixteen timber species are recommended for decorative veneer and decorative plywood (Anon, 1986), 17 for marine plywood (Anon 1985), 46 for manufacture of ply for general purposes (Anon, 1983), 36 for plywood and battens for tea chest (Anon, 1979).

Ghora neem (Melia azedarach) is a fast growing medium sized, handsome deciduous tree with a spreading crown; branchlets slender; young shoots and inflorescence covered with stellate hairs. Bark greenish brown or purlish, smooth, lenticellate in young trees, blakish brown. The trees grow fast and coppices very well (Das and Alam, 2001). The tree is a native of Baluchistan and Kashmir and naturalized in Bangladesh. More commonly found in North Bengal, usually planted as roadside avenue trees along highways, railways tracks, in parks and gardens and in village shrubberies. Sometimes found in certain forests of Sylhet, Chittagong, Dhaka, Mymensingth and Dinajpur as an escape (Das and Alam, 2001). Wood is reddish or pinkish brown, light and suitable for furniture, veneering and sport goods etc. (Das and Alam, 2001). Ghora neem is used as one of the species for agro-forestry system (Hasan and Alam, 2006). It is planted as a major species in village forest and social forest in Bangladesh (BFD, 2011).

\footnotetext{
*Corresponding author. e-mail: atanu03ku@yahoo.com
} 
The expansion of plantation of ghora neem and fast growing characteristic are the great scope to use it for better purposes. As lacking of raw material is an acute problem for wood based industry in Bangladesh, it is thus an imperative to find out the quick growing species for wood based industry. Therefore, this study was carried out to find out the physical and mechanical properties of ghora neem plywood to asses it as a raw material for manufacturing plywood.

\section{Materials and methods}

Two ghora neem (Melia azedarach) trees were collected from the village Baniajhuri, Ghior upazilla under Manikganj district in Bangladesh. The age of the trees was approximately 7 to 8 years. The height of the trees was $80.0 \mathrm{~cm}$ to 100.0 $\mathrm{cm}$ and diameter $63.5 \mathrm{~cm}$ to $76.2 \mathrm{~cm}$. While making selection, trees with excessive clean, straight boles were preferred.

The logs were cross cut lengthwise by hand saw to convert into bolt of $140.0 \mathrm{~cm}$. Then the bolt was ready to be conveyed into the plant for peeling. The veneers were produced from bolt in two veneer lathes and the thickness of core veneers was $0.25 \mathrm{~cm}$.

Veneers were clipping manually and these were conveyed through a long chamber of Automatic Roller Track Veneer Drier for drying. The temperature range was $135^{\circ} \mathrm{C}$ to $145^{\circ} \mathrm{C}$ and total required time was 45 minutes. After drying, the veneers were clipped by josting veneer cutting machine in widthwise to size, and into smaller strips for removed defective material.

Plywood was made by gluing the plies together with the use of urea -formaldehyde resins as the adhesive. The adhesive was spreaded on alternative layers of ply manually. The glue coated veneers were allowed assembly time for 25 minutes between the spreading of adhesive and the application of pressure.

The glue-coated veneers were assembled in proper order to ensure proper alignment of components and intimate contact between the veneer and the glue. Pressing of the assembled plies was done in a multi-plate ten hot press. For making 1.2 $\mathrm{cm}$ thick plywood, the board was pressed at $8 \mathrm{MPa}$ for 8 minutes and it was performed by two steps. At first step, the pressure was applied for 3 minutes in order to remove air between veneer layers. Then the pressure was applied for 5 minutes. The temperature of $120^{\circ} \mathrm{C}$ was used for making this plywood.

The dimension of the trimmed plywood was 240.0 $\mathrm{cm} \times 120.0 \mathrm{~cm}$. The trimmed plywood was sanded by sand paper number 1.50 inch. After sanding, some defects were appeared on the surface of the plywood and these were removed by sigel manually. The plywood was stored in the conditioning room for 12 hours.

Shimul plywood as a market plywood was collected from Akij Particleboard Mills Ltd. which was produced using same procedure (personal communication). For testing the physical properties, the samples were $50 \mathrm{~mm} \times 50 \mathrm{~mm} \times 12$ $\mathrm{mm}$ while these were $240 \mathrm{~mm} \times 25 \mathrm{~mm} \times 12 \mathrm{~mm}$ for mechanical properties. Physical properties of plywood were tested in the laboratory of Forestry \& Wood Technology Discipline, Khulna University, Khulna. Mechanical properties of plywood were tested in the laboratory of Akij Particleboard Mills Ltd.

All data collected from the various tests result for determining the performance of ghora neem plywood were analyzed by using Microsoft office excel 2007 and SPSS 12.0.

\section{Results and discussions}

\section{Physical properties}

The density of ghora neem plywood was $541 \mathrm{~kg} / \mathrm{m}^{3}$ while the density of shimul plywood was $499.80 \mathrm{~kg} / \mathrm{m}^{3}$. In all the cases the thickness of the plywood was $12 \mathrm{~mm}$. This difference of density among the plywood of different species of equal thickness is due to the differences of wood densities among these species. The wood density of ghora neem is 430 $\mathrm{kg} / \mathrm{m}^{3}$ and it is higher than shimul $370 \mathrm{~kg} / \mathrm{m}^{3}$ (Sattar et al., 1995). The statistical analysis shows that there is a significant difference between two types of plywood (Table I). The density range of the standard plywood is 430 to $790 \mathrm{~kg} / \mathrm{m}^{3}$ (Franz et al., 1975). Ghora neem plywood follows the standard.

From the study it was found that the water absorption of ghora neem plywood was $63.67 \%$ which was lower than that of shimul plywood (107.32\%) (Fig. 2). The density of ghora neem plywood $\left(541 \mathrm{~kg} / \mathrm{m}^{3}\right)$ is higher than that of shimul plywood $\left(499.80 \mathrm{~kg} / \mathrm{m}^{3}\right)$. Sulastiningsih et al. (1996) reported 


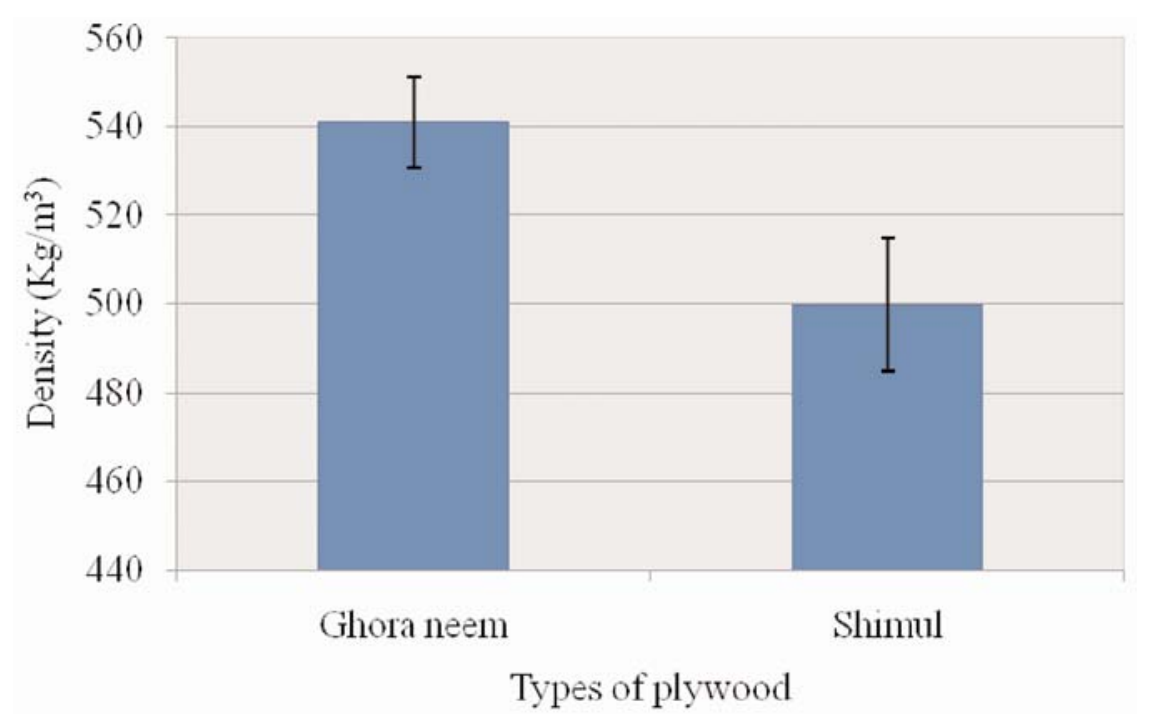

Fig. 1. Density of ghora neem plywood and shimul plywood

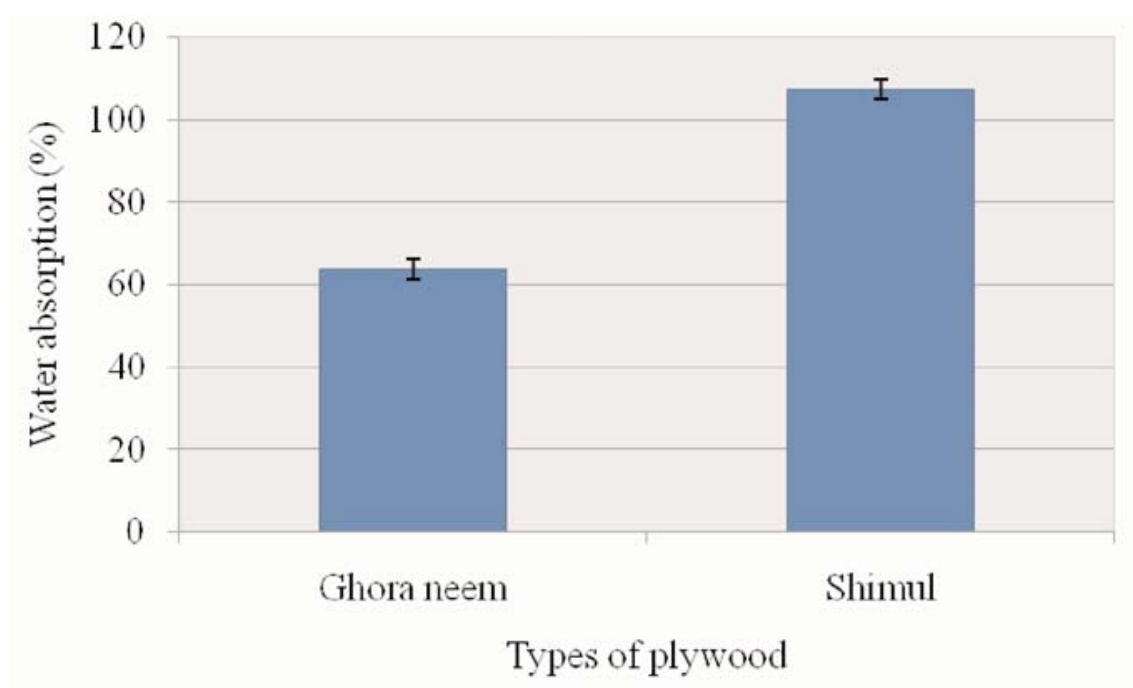

Fig. 2. Water absorption of ghora neem plywood and shimul plywood

that water absorption decreased with increasing board density. Significant difference was found between two types of plywood for water absorption (Table I).

After 24 hours submersion in water, the thickness swelling for ghora neem plywood was found $2.51 \%$ (Fig. 3). On the other hand, shimul plywood showed 3.16\%. In general, the thickness swelling has a tendency to increase with decreasing board density after a long duration of water immersion (Hermawan, 2001). Ghora neem plywood showed higher density in comparison to shimul plywood. Statistically it is

Table I. Summary of analysis of Independent Sample t-test of physical properties

\begin{tabular}{lccc}
\hline Density & Water Absorption (\%) & Thickness swelling (\%) & Linear Expansion (\%) \\
\hline $\mathrm{t}=14.89, \mathrm{df}=8$, & $\mathrm{t}=-8.53, \mathrm{df}=8$, & $\mathrm{t}=-1.86, \mathrm{df}=8$, & $\mathrm{t}=1.69, \mathrm{df}=8$, \\
$\mathrm{P}<0.05^{*}$ & $\mathrm{P}<0.05^{*}$ & $\mathrm{P}<0.05^{*}$ & $\mathrm{P}<0.05^{*}$ \\
\hline
\end{tabular}

Note: $*=$ Significant at $95 \%$ probability level 


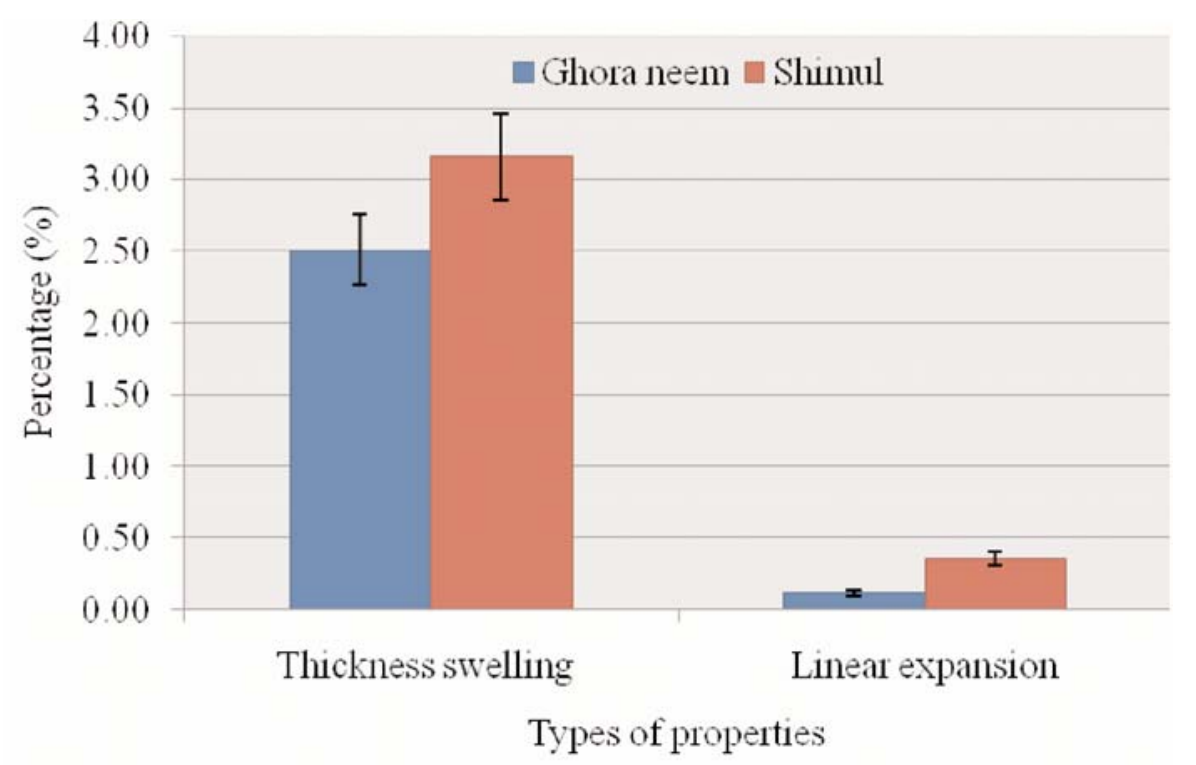

Fig. 3. Thickness swelling and linear expansion of ghora neem plywood and shimul plywood

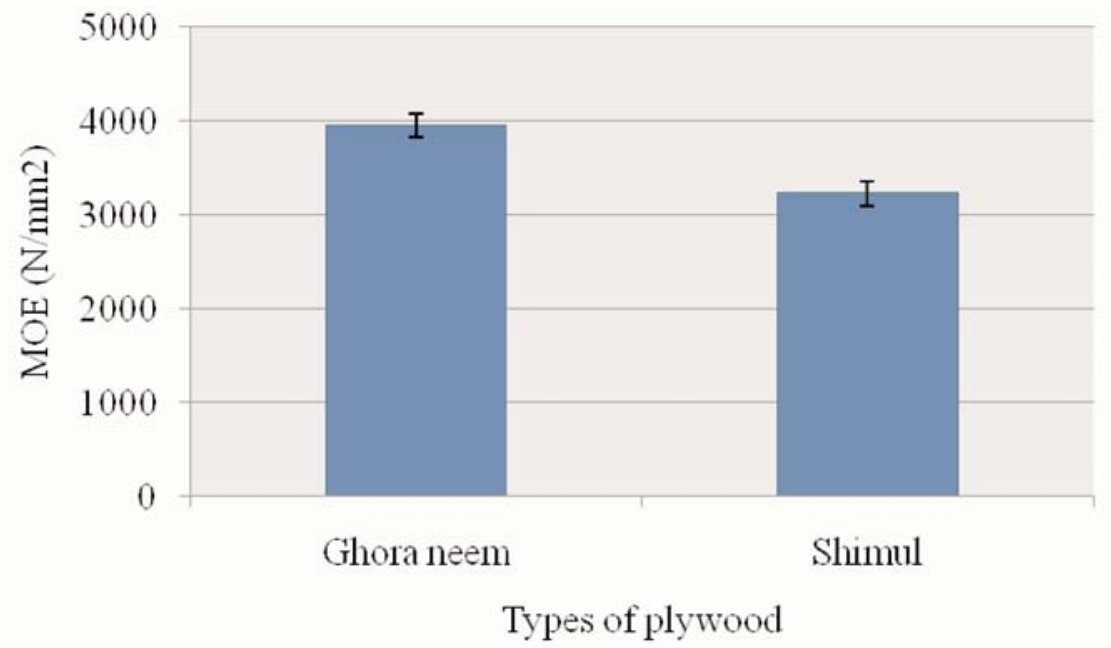

Fig. 4. MOR of ghora neem plywood and shimul plywood

found that there is significant difference between two types of plywood (Table I).

The linear expansion of ghora neem plywood and shimul plywood were 0.12 and $0.36 \%$ respectively (Fig. 3 ). The linear expansion of ghora neem plywood is significantly different from the linear expansion of shimul plywood (Table I).

\section{Mechanical properties}

It was evaluated from the study that the modulus of rupture (MOR) of ghora neem was $58.33 \mathrm{~N} / \mathrm{mm}^{2}$ but it was 32.52 $\mathrm{N} / \mathrm{mm}^{2}$ for the shimul plywood (Fig. 4). Higher density has a great influence on MOR (Kwon and Geimer, 1998; Ajayi, 2002; Zheng et al., 2007). The density of ghora neem plywood was more than that of shimul plywood. Significant difference has been found between two types of plywood for MOR (Table II). According to ASTM D3043-87, the standard range of MOR is 20.70 to $48.30 \mathrm{~N} / \mathrm{mm}^{2}$. The MOR of ghora neem is $58.33 \mathrm{~N} / \mathrm{mm}^{2}$ and it satisfies the standard.

The Modulus of elasticity (MOE) of ghora neem plywood was found $3950.01 \mathrm{~N} / \mathrm{mm}^{2}$ and $3224.15 \mathrm{~N} / \mathrm{mm}^{2}$ was examined for shimul plywood (Fig. 5). Statistical analysis has been informed about the significant difference between two types of plywood (Table II). The MOE is higher for high 


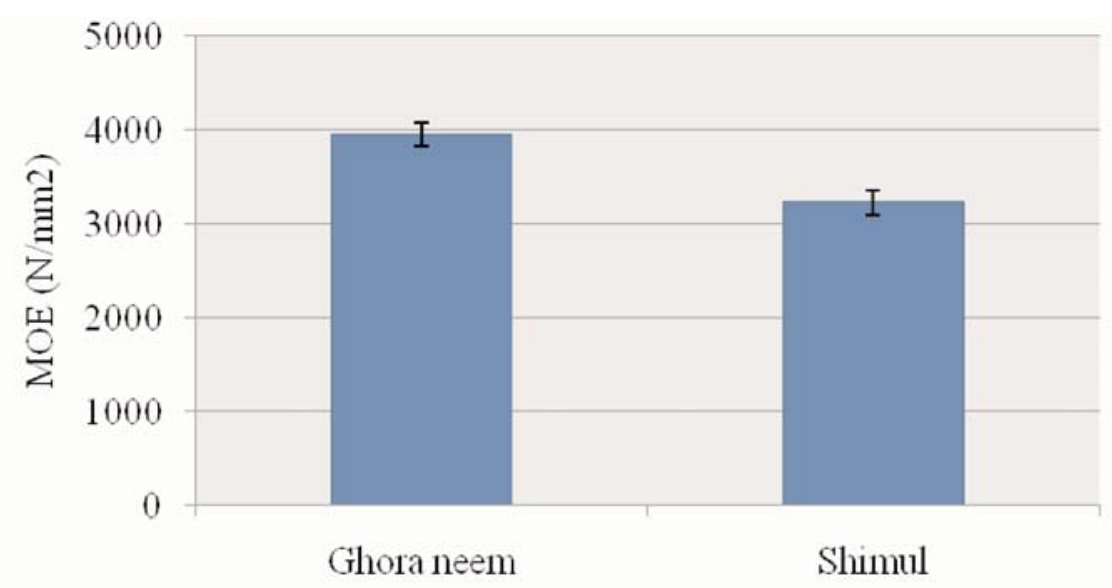

Types of plywood

Fig. 5. MOE of ghora neem plywood and shimul plywood

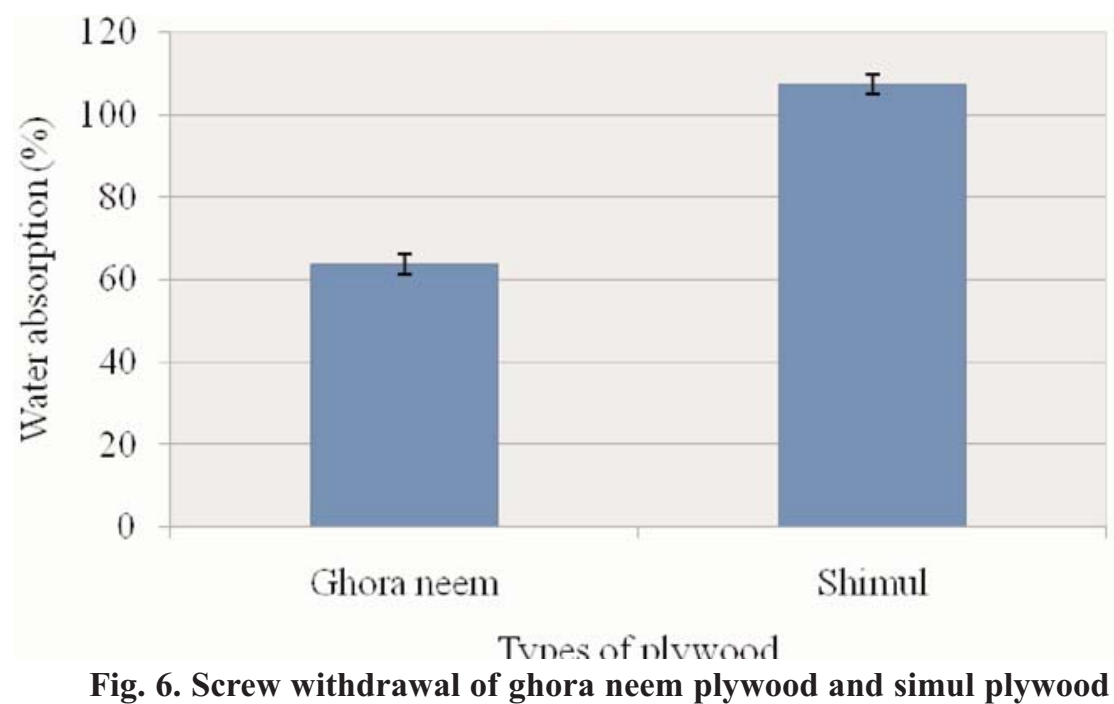

Table II. Summary of analysis of Independent Sample t-test of mechanical properties

\begin{tabular}{lcc}
\hline MOR & MOE & Screw withdrawal \\
\hline $\mathrm{t}=7.21, \mathrm{df}=8, \mathrm{P}<0.05^{*}$ & $\mathrm{t}=5.32, \mathrm{df}=8, \mathrm{P}<0.05^{*}$ & $\mathrm{t}=25.53, \mathrm{df}=8, \mathrm{P}<0.05^{*}$
\end{tabular}

Note: $*=$ Significant at $95 \%$ probability level

density board (Kwon and Geimer, 1998; Ajayi, 2002; Zheng et al., 2007). The standard value of MOE is 6890 to 1310 $\mathrm{N} / \mathrm{mm}^{2}$ (ASTM D3043-87) and this standard is followed by the ghora neem plywood.

It was observed that the screw withdrawal was $168.8 \mathrm{~kg}$ for ghora neem plywood. The screw withdrawal was found $75.96 \mathrm{~kg}$ for shimul plywood (Fig. 6). The screw withdrawal of ghora neem plywood is significantly different from the screw withdrawal of shimul plywood (Table II). Generally it is believed that wood of higher density pose higher resist- ance to screw withdrawal in comparison to wood of lower density (Eckelman, 1975).

\section{Conclusion}

Properties are the indicator for using a raw material for particular products. Physical and mechanical properties of ghora neem plywood were higher than that of shimul plywood. The important properties of ghora neem plywood follow the standard. It can be a good source of raw material for plywood industries considering the properties. This will 
reduce the pressure on the single raw material and will maintain the continuity of production of plywood.

\section{References}

Ajayi B (2002), Preliminary Investigation of CementBonded Particle board from Maize Stalk Residues. Nig J. For. 32: 33-37.

Anon. (1979), Bangladesh Standard Specification for plywood tea chests (1st revision) BDS 18:1978. 3-DIT Avenue, Motijheel Commercial Area, Dhaka-2, Bangladesh, pp. 28.

Anon. (1983), Bangladesh Standard Specification for plywood. for general purposes (1st revision) BDS 799: 1983. 3-DIT Avenue, Motijheel Commercial Area, Dhaka-2, Bangladesh, pp. 21.

Anon. (1985), Specification for wood particleboards (medium density) for general purposes (First revision). IS: 3087-1985. Indian Standard Institution, New Delhi, pp. 19.

Anon. (1986), Bangladesh standard specification for veneered decorative plywood. BDS 1158: 1986. Bangladesh Standard and Testing Institution, 116/A, Tejgaon Industrial Area, Dhaka-1208, Bangladesh, pp. 9.

ASTM. (Current edition). Annual Book of ASTM Standards. Philadelphia, PA: American Society for Testing and Materials.

ASTM D3043-87. Standard methods of testing structural panels in flexure.

ASTM D3500-90. Standard test methods for structural panels in tension.

Baldwin RF (1981), Plywood manufacturing practices revised 2nd edition. Miller and Freeman Publication Inc. USA. Bamboo-Cement Board.

BFD (2011), Forest types. http://www.bforest.gov.bd/ index.php/ forest-category/village-forests.

Das DK (1990), List of Bangladeshi Village tree species. (Bangladesh Forest Research Institute, Chittagong, Bangladesh.

Das DK and Alam MK (2001), Trees of Bangladesh, Bangladesh Forest Research Institute, Chittagong, Bangladesh.

Eckelman CA (1975), Screwholding Performance in Hardwoods and Particleboard, For Prod J, 25(6): 30-35.
Franz FP, Kollmann EW and Kuenzi AJS (1975), Principles of wood science and Technology. Vol.II Wood based materials, Springer Verlag, New York, pp. 550.

Hasan MK and Alam AKM (2006), Land Degradation Situation in Bangladesh and Role of Agroforestry. $J$ Agric Rural Dev 4(1\&2): 19-25.

Hermawan D (2001), Manufacture of cement-bonded particleboard using carbon dioxide curing technology. A Dissertation present to the Department of Forest and Biomass Science, Graduate School of the Faculty of Agriculture, Kyoto University, Japan.

Hrázský J and Král P (2007), A contribution to the properties of combined plywood materials. J Forest Sci 53: 285-292.

Král P and Hrázský J (2006), Efects of diferent pressing conditions on properties of spruce plywoods. J. Forest Sci, 52: 285-292.

Kwon H.E and Geimer RL (1998), Impact of Steam Pressing Variables on the Dimensional Stabilisation of Flakeboards. For. Prod. J, 48: 55- 61.

Sattar MA, Bhattacharjee DK and Sarker SB (1995), Physical, Mechanical and Seasoning Properties of 45 Lesser Used or Unused Forest Timbers of Bangladesh and Their Uses. Bangladesh Journal of Forest Science, 24(2):11-21.

Sulastiningsih IM, Tambunan B, Yulia Y and Santoso A (1996), Some properties of Bamboo-Cement Board. In: Proceedings of the 1st International Wood Science Seminar. Kyoto, Japan, pp. 83-91.

Youngquist JA. (1988), Wood-based composites: The panel and building components of the future. In: proceedings, IUFRO Division 5, Forest products subject group 5.03: wood protection; 1987 May 16-17; Honey harbour, Canada, pp. 5-22.

Zaman MA (1982), Manufacture of commercial plywood and tea chests in Bangladesh and various problem faced by the industry. Proceedings of the second national forestry conference Bangladesh, held at sishu academy Dacca, pp. 310-315.

Zheng Y, Zhongli LP, Zhang RH, Jenkins BM and Blunk S (2007), Particleboard Quality Characteristics of Saline Jose Tall Wheatgrass and Chemical Treatment Effect. Bioresource Tech 98: 1304-1310.

Received: 03 June 2013; Revised: 05 November 2013; Accepted: 02 January 2014. 